Article

\title{
Deciphering the Spatial Structures of City Networks in the Economic Zone of the West Side of the Taiwan Strait through the Lens of Functional and Innovation Networks
}

\author{
Yan Ma * and Feng Xue \\ School of Architecture and Urban-Rural Planning, Fuzhou University, Fuzhou 350108, Fujian, China; \\ N181520027@fzu.edu.cn \\ * Correspondence: mayan@fzu.edu.cn
}

Received: 17 April 2019; Accepted: 21 May 2019; Published: 24 May 2019

check for updates

\begin{abstract}
Globalization and the spread of information have made city networks more complex. The existing research on city network structures has usually focused on discussions of regional integration. With the development of interconnections among cities, however, the characterization of city network structures on a regional scale is limited in the ability to capture a network's complexity. To improve this characterization, this study focused on network structures at both regional and local scales. Through the lens of function and innovation, we characterized the city network structure of the Economic Zone of the West Side of the Taiwan Strait through a social network analysis and a Fast Unfolding Community Detection algorithm. We found a significant imbalance in the innovation cooperation among cities in the region. When considering people flow, a multilevel spatial network structure had taken shape. Among cities with strong centrality, Xiamen, Fuzhou, and Whenzhou had a significant spillover effect, which meant the region was depolarizing. Quanzhou and Ganzhou had a significant siphon effect, which was unsustainable. Generally, urbanization in small and midsize cities was common. These findings provide support for government policy making.
\end{abstract}

Keywords: city network; spatial organization; people flows; innovation network

\section{Introduction}

In the process of globalization, megacity regions are playing an increasingly important role in China's regional development. Megacity regions are planned areas that are expected to create new growth poles during a region's economic development. Whether defined as metropolitan regions or megacity regions, these regions must create interconnections with existing cities and towns $[1,2]$. Therefore, a reasonable evaluation of cities' interconnections in a given region should be the basis for regional planning and decision making [3,4]. In traditional regional analysis, cities should interact with adjacent big cities. Although researchers have been concerned with flow space, the urban system based on scale has gradually transformed into a network paradigm [5-7]. On the basis of this transformation, relationships among cities have been continuously reconstructed and redefined, and the development of intercity relationships has emerged as an important issue that needs to be studied in depth.

Since the development of communication technology and transportation infrastructure, cities have developed economic and production connections even when they lack direct physical relationships. Therefore, researchers have begun to focus on city network analysis based on the flow of people, information, capital, and traffic [8,9]. These interconnections within a megacity region form a network for cities to exchange production and economic factors $[10,11]$. These regions have abundant characteristics, including multiple types of flow, in numerous directions, and of various strength. Thus, 
some researchers have begun to evaluate the integration status of megacity regions by classifying the types of flow into physical (mainly by transportation network), functional (mainly by people, capital), and innovative areas [12-14]. In such research, the complexity of city networks has been a concern, and more attention has been given to discussions about regional integration rather than to the creation of systems with interregional or interlocal links. The approach taken to analyzing city network structures has included centrality analysis [15-18] and the core-periphery model $[19,20]$. Although most research has characterized cities' hierarchies and structures at the regional scale, only a few scholars have looked inside the network by dividing groups into cohesive subgroups $[17,18,21]$ or communities using a discovery algorithm based on intercity links [13,15,22-25].

In recent years, innovation has become the core driving force in urban and regional socioeconomic development. The innovation network has emerged as a new research direction for city networks [26,27]. Scholarly research on the innovation network has focused primarily on connections between innovative subjects and connections between industrial clusters at the regional scale [28]. Scholars also have examined the output of scientific cooperation and technical cooperation on national and global scales $[29,30]$. As an important production factor, the flow of people reflects the functional interconnections that exist between cities and towns. Thus, the present work will examine the spatial structure and city network from this perspective.

In 2009, the State Council issued "Several Opinions on Supporting Fujian Province to Accelerate the Construction of the Economic Zone on the West Side of the Taiwan Strait" (the Economic Zone of WSTS), which marked its transition from an area with local decision-making authority in Fujian Province to an area following the national strategy. Few studies have examined the city connections within this region. The national development strategy has paid more attention to promoting the region as a new economic pole within the WSTS. The need to identify the spatial structures of these city networks is urgent, however, so that this information can be used to provide decision-making support for appropriate policies on a theoretical level and also to study the effects on regional sustainable development. Thus, the target of this research was to identify the spatial structures of city networks at two different scales in the Economic Zone of the WSTS. We measured the strength and direction of intercity links among the study area and characterized the city network structure at different scales from different perspectives to provide support for government policy making. In addition, we provided a theoretical reference for regional resource allocation to ensure more sustainable and balanced regional development. The present work contributes to the research not only by analyzing the city network in a megacity region on different spatial scales but also by considering the direction of these links.

The remainder of this paper is organized as follows: Section 2 introduces the data sources, the research framework, and the research methods. Section 3 describes the city network structure from the regional and local scales by introducing the research area and constructing the functional and innovation networks. Section 4 summarizes the research results, proposes corresponding policy recommendations, and notes shortcomings.

\section{Methodology}

\subsection{Research Area}

The Economic Zone of WSTS is located on the southeast coast of China (Figure 1), across from the provinces of Fujian, Zhejiang, and Guangdong (Figure 2). As an important part of the two sides of the Taiwan Strait and the junction of the Yangtze River Delta Economic Zone and the Pearl River Delta Economic Zone, this zone has a special status and importance in regard to the regional spatial situation of China's economic development. The research area consists of 20 prefecture-level cities, namely: Xiamen, Fuzhou, Quanzhou, Zhangzhou, Longyan, Nanping, Ningde, Sanming, and Putian in Fujian Province; Wenzhou, Lishui, and Quzhou in Zhejiang Province; Chaozhou, Meizhou, Jieyang, and Shantou in Guangdong Province; and Fuuzhou, Ganzhou, Shangrao, and Yingtan in Jiangxi Province (as Fuzhou in Jiangxi Province and Fuzhou in Fujian Province have the same name in 
English, this paper spells the city in Jiangxi Province "Fuuzhou" to distinguish it from Fuzhou in Fujian Province.) In 2017, for the case area, the population was 95.78 million and the land area was 270,000 square kilometers. Figure 3 shows that Wenzhou, Quanzhou, Ganzhou, Fuzhou, and Shangrao have the five largest populations in the region. From the perspective of gross domestic product (GDP), Quanzhou, Fuzhou, Wenzhou, Xiamen, and Zhangzhou have the five highest GDPs in the region; Xiamen, Fuzhou, Quanzhou, Longyan, and Sanming are the five cities with the highest per capita GDP.

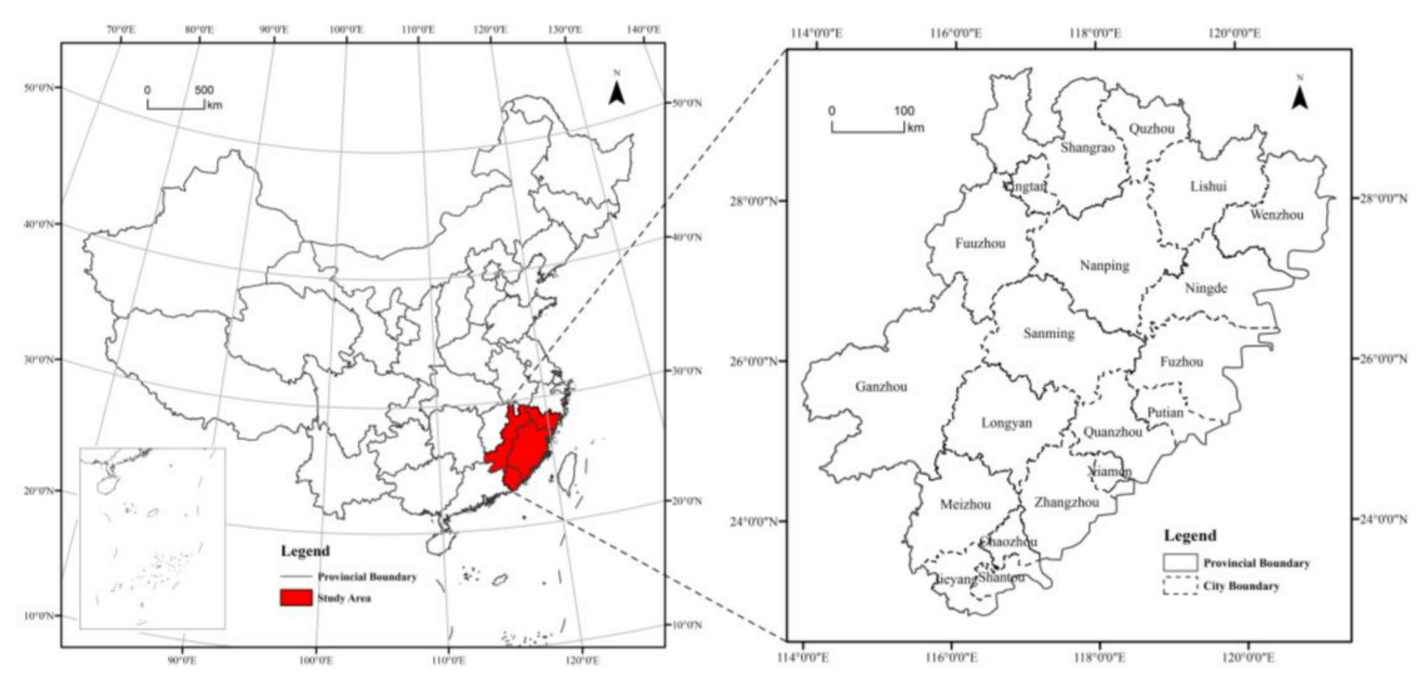

Figure 1. Location map of the Economic Zone of WSTS and its districts: (a) geographic location of the study area; and (b) administrative districts of the study area.

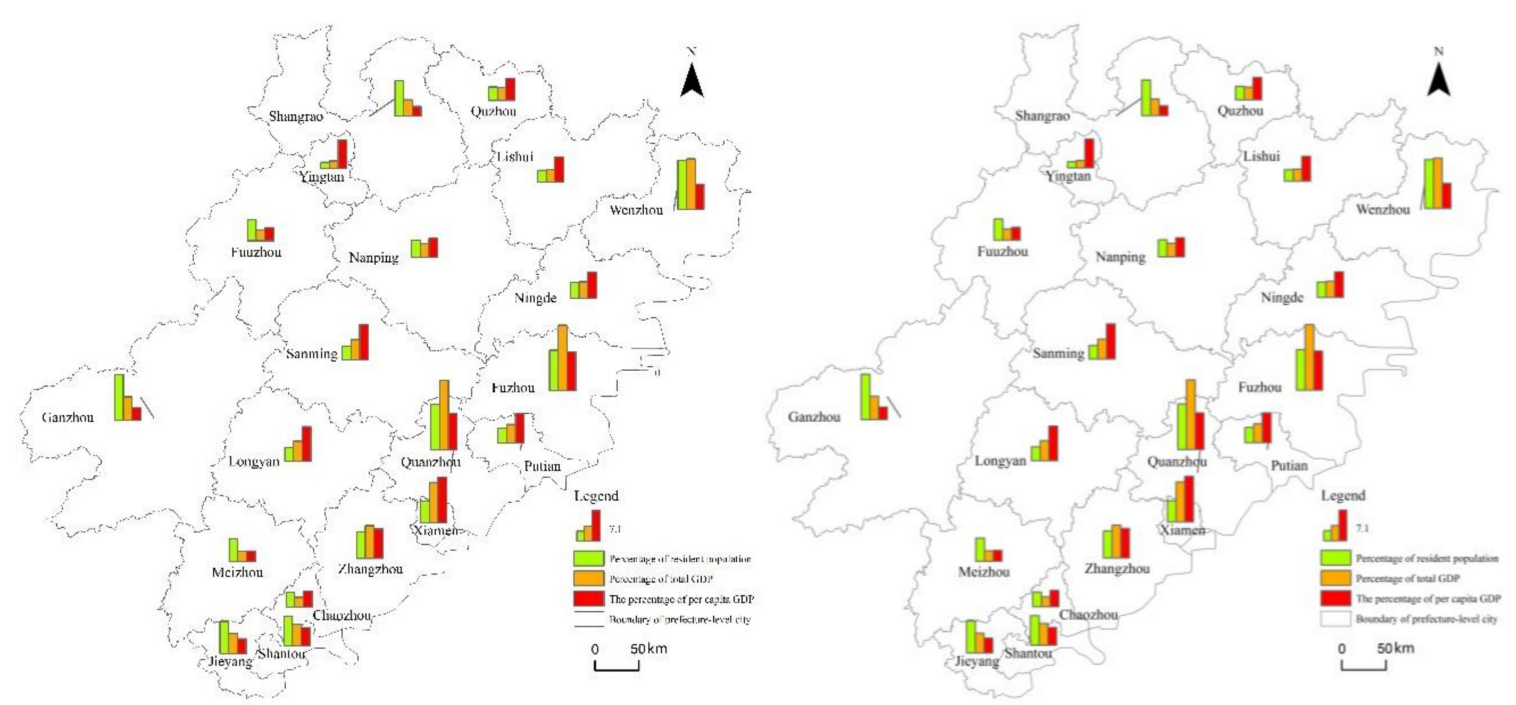

Figure 2. The social and economic situation of the Economic Zone of WSTS (Note: Data are from the Fujian Statistical Yearbook (2018), Guangdong Statistical Yearbook (2018), and Zhejiang Statistical Yearbook (2018).

\subsection{Data Sources}

The intercity flow of people represents the functional connections between cities, and the purpose of people flow is often reflected in the functional connections between cities [31]. In particular, in the context of rapid urbanization in China, intercity people flow has become increasingly frequent. As a result, it often becomes an important driving force for socioeconomic development and urbanization through spatial reallocation and recombination with other elements [32,33]. 
This study described the characteristics of regional functional networks by portraying people flow in the Economic Zone of WSTS. The data for the flow of people come from the platform of Tencent Position Big Data, which were collected in 2016. Data include information about migration times, travel modes, and migration directions. The data are semi-structured. To reduce the influence of data fluctuation on this analysis, we calculated the standard deviations of people flow data on seven weekdays (April 26-May 11) and seven weekends (April 3-May 28) in 2016, excluding holidays that would lead to obvious data noise. The statistical results of the data collection are shown in Figure 3 and Table 1. In Figure 3, the length of the box reflects the degree of data dispersion. The longer the box, the more discrete the data. Finally, we took the data on April 28 and May 14 in the research area to represent the flow of people on weekdays and weekends, respectively, which showed the minimum standard deviation during the observation period.

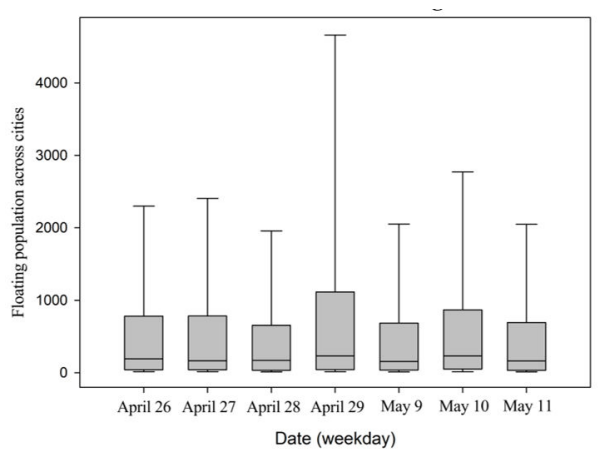

(a)

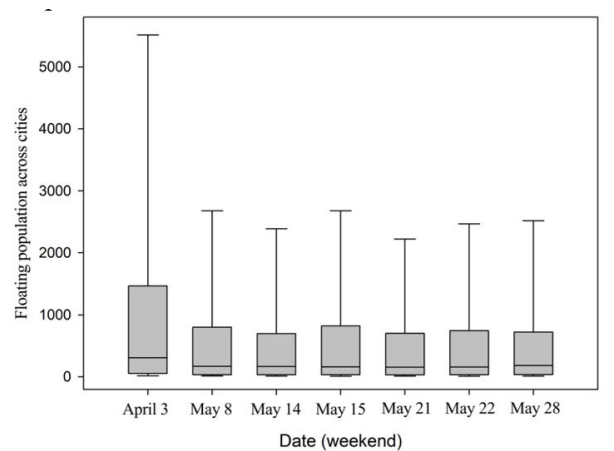

(b)

Figure 3. The box plots of people flows on (a) weekdays and (b) weekends.

Table 1. Descriptive statistics of people flow data on weekdays and weekends.

\begin{tabular}{cccccc}
\hline Date & Average & Standard Deviation & Median & Maximum & Minimum \\
\hline April 3 & 2308.09 & 6580.537 & 309 & 64,837 & 2 \\
April 26 & 1042.958 & 2782.742 & 191.5 & 20,889 & 1 \\
April 27 & 1062.071 & 2883.85 & 165 & 21,920 & 1 \\
April 28 & 894.388 & 2430.667 & 170 & 18,116 & 1 \\
April 29 & 1933.426 & 5515.523 & 232.5 & 52,075 & 1 \\
May 8 & 1265.929 & 3707.691 & 172 & 33,272 & 1 \\
May 9 & 986.3842 & 2799.771 & 156.5 & 21,618 & 1 \\
May 10 & 1234.703 & 3160.43 & 231.5 & 24,518 & 1 \\
May 11 & 925.278 & 2510.338 & 161.5 & 19,035 & 1 \\
May 14 & 1135.575 & 3451.58 & 167 & 31,577 & 1 \\
May 15 & 1349.989 & 4163.396 & 162 & 42,022 & 1 \\
May 21 & 1080.435 & 3200.805 & 157 & 29,377 & 1 \\
May 22 & 1233.206 & 3735.8 & 159 & 36,570 & 1 \\
May 28 & 1193.293 & 3545.245 & 183 & 32,650 & 2 \\
\hline
\end{tabular}

The innovation network included a number of the city-dyad's common patents. The data come from the official website of the World Intellectual Property Organization and are from the period from January 2000 to November 2018.

\subsection{Research Framework}

As shown in Figure 4, to provide policy-making support to promote the sustainability of the study area, we first constructed a functional network and an innovation network through a number of floating populations across cities and patents shared among cities in Geographic Information System (GIS). To improve the readability of the network figures, we identified the city-dyads with strong or weak connections in the region. To further describe intercity relationships in the region, we calculated 
the degree of centrality of the cities and classified them accordingly so that we could characterize network structures at the region scale.

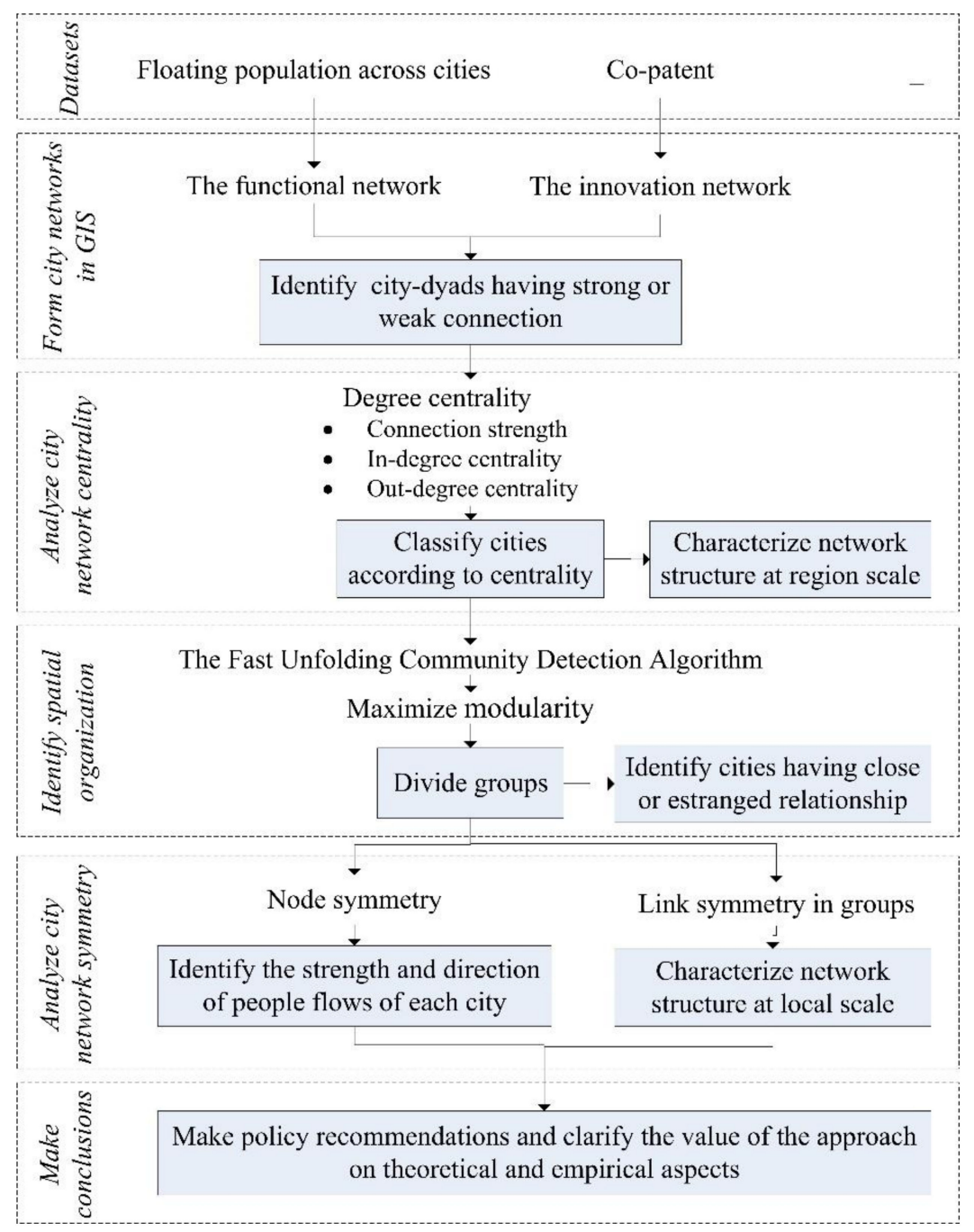

Figure 4. The research framework.

The existing research tends to characterize city network structures at the regional scale $[3,34]$. Sometimes, however, it is limited in its capacity to capture the complexity of city networks on a microlevel. So on the basis of characterizing the city network structure at the regional scale, we tried to further characterize the network structure at the local scale. Specifically, we identified the spatial organization by maximizing the modularity, which was related to the quality of group-dividing results, and we identified cities that had close or estranged relationships. Spatial organization, however, cannot reflect the direction of these links. To further explore intercity relationships in each group, the study calculated link symmetry in each group. Therefore, we could characterize intercity relationships at a microlevel. Meanwhile, to characterize each city's role in the region, we calculated node symmetry to identify the direction of people flows in each city as a supplement to urban centrality. To some extent, the study further responded to the complexity and dynamics of city networks. Finally, to improve the applicability of the results, we provided policy recommendations and clarified the value of the approach in regard to theoretical and empirical aspects. 


\subsection{Approaches to Characterize Network Centrality, Spatial or Ganization, and Network Symmetry}

\subsubsection{Network Centrality}

Degree of centrality is the most direct index used to characterize urban centrality [33]. The greater the degree of centrality of a city, the more important the city is, and the greater its centrality [35]. Specifically, city degree centrality refers to the number of cities that connect relatively closely to the city. In a directed network, we divided the degree of centrality into in-degree centrality and out-degree centrality, where the out-degree centrality represented a city's radiation capacity, and the in-degree centrality represented a city's absorptive capacity. In addition, in an undirected network, the degree of centrality represented the urban connection strength in the network. The formula is as follows [17]:

$$
C D(i)=\sum_{j=1}^{n} X_{i j}
$$

where $C D(i)$ represents out-degree centrality or in-degree centrality of city $i$ in the directed network, and indicates the number of cities that connect relatively closely with city $i$ in the undirected network; and $X_{i j}$ presents the directed connection value of city $i$ and city $j$ in the directed network, and presents undirected connection value of city $i$ and city $j$ in the undirected network.

\subsubsection{Network Symmetry}

The direction of city interaction generally is expressed by symmetry. To quantify the symmetry, Narisra Limtanakool proposed the Node Symmetry Index and the Link Symmetry Index [25]. The former emphasizes the direction of the elements flowing in a city, whereas the latter emphasizes the direction of the elements flowing between cities. Together, they reflect the direction of intercity interaction.

Node symmetry is used to describe the city symmetry reflected by in-degree centrality and out-degree centrality. In-degree centrality and out-degree centrality, however, do not reflect the size of the population across cities, so this paper combined the concept of effective flow rate [36] to optimize node symmetry. For node $i$

$$
N S I_{i}=\frac{\sum I_{i}-\sum O_{i}}{\sum I_{i}+\sum O_{i}}
$$

where $I_{i}$ refers to the number of inflowing people of city $i$ from other cities in the region; $O_{i}$ refers to the number of outflowing people of city $i$ from other cities in the region. When $N S I_{i}=-1$, city $i$ net outflows people, and when $N S I_{i}=1$, city $i$ net inflows people.

Link symmetry is used to determine the level of asymmetry in city links, but NSI cannot reflect the direction of links. Liu proposed the modified link symmetry $L S \Gamma$, which not only can determine the level of the asymmetry of links but also can judge the direction of links [37]. The calculation formula is as follows:

$$
L S \Gamma_{i j}=2 f_{i j}-1
$$

where $f_{i j}$ refers to the ratio of the traffic that from node $i$ to node $j$ to the traffic from node $i$ and node $j$. When $L S \Gamma_{i j}<0$, the flow from node $i$ flow to node $j$ is smaller than the flow from node $j$ flow to node $i$. When $L S \Gamma_{i j}=0$, the link is a bidirectional equivalent flow. When $L S \Gamma_{i j}>0$, the flow from the node $i$ flow to the node $j$ is greater than the flow from the node $j$ flow to the node $i$.

\subsubsection{Spatial Organization}

Spatial organization is often characterized by the index of the group structure, which reflects the relative strength of intercity interaction. The network is differentiated into groups with relatively close internal nodes in a group and relatively loose relationship with other groups. It is of great significance for discovering implicit modes and internal organizations of the network and for predicting 
its behavior [38]. The Fast Unfolding Community Detection algorithm based on modularity performed well in both efficiency and effect and was easy to understand [23]. This method took the module degree as the most important indicator, and its goal was to maximize the module degree. Modularity is a standard proposed by Newman to measure the obviousness of network group structure [24], which is an inherent attribute value of networks. The formula is as follows:

$$
Q=\frac{1}{2 m} \sum_{i j}\left(A_{i j}-\frac{k_{i} k_{j}}{2 m}\right) \delta\left(C_{i}, C_{j}\right)
$$

where $A_{i j}$ is the edge weight between nodes $i$ and $j$, which represents the sum of all edges' weights in the network; $k_{i}$ and $k_{j}$ represent the degree value of node $i$ and node $j$ in an unweighted network; $C_{i}$ represents groups where the node $i$ is located; $C_{j}$ represents groups where the node $j$ is located; $m$ represents the maximum number of connections that may exist in the network. The $Q$ value, which represents modularity, was between 0 and 1 , and the closer the modularity to 1 , the more obvious the group structure was. The modularity was usually between 0.3 and 0.7 [16], so when the modularity was less than 0.3 , we considered that the group structure of the network was not obvious, that is, the quality of group division was poor.

\section{Results}

\subsection{Network Construction and Analysis}

\subsubsection{Functional Network}

The present research uses the size of the floating population across cities to characterize the strength of intercity people links and builds the functional network of the Economic Zone of WSTS on the basis of the links. According to the time, the people flow was divided into the people flow on weekdays and the people flow on weekends. We assumed that business was the main purpose of intercity flow on weekdays, and tourism was the main purpose of intercity flow on weekends.

Referring to the threshold division of natural break points, the study defined an intercity flow of less than 1100 people to be insignificant people links, more than 12,000 but less than 28,000 to be the main people links, and more than 28,000 people to be core people links.

The study found that on weekdays (Figure 5), the core people links occurred in Xiamen-Quanzhou, Xiamen-Zhangzhou, and Shantou-Jieyang, and on weekends, Shantou-Chaozhou also experienced core people links. From the perspective of administrative jurisdiction and locations, these were all border cities in the same province. The significant people links created a structure of an outer ring shape around the region and a diamond shape inside Fujian Province, both on weekdays and on weekends. Most of these links were distributed along the eastern coast of the region. The main people links that occurred on weekends were in Xiamen-Zhangzhou, Quanzhou-Xiamen, Jieyang-Shantou, Chaozhou-Shantou, Fuzhou-Ningde, Fuzhou-Putian, Fuzhou-Quanzhou, Putian-Quanzhou, and Fuzhou-Xiamen, and $88.9 \%$ of these links were between border cities in the same province. On weekdays, in addition to the main people links from the weekends, Fuzhou-Nanping also was included in the main people links. Of these links, $90 \%$ of them occurred at border cities in the same province. Therefore, the intercity business connections and tourism connections in the region were subject to some restrictions of distance. Compared with nonadjacent cities and cities in different provinces, people were more inclined to have business cooperation with, and short-distance travel to, border cities in the same province. 


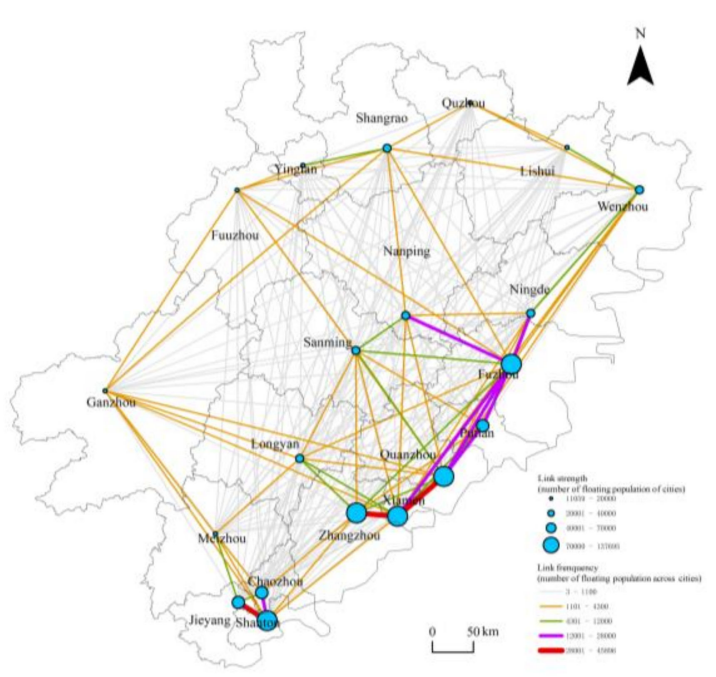

(a)

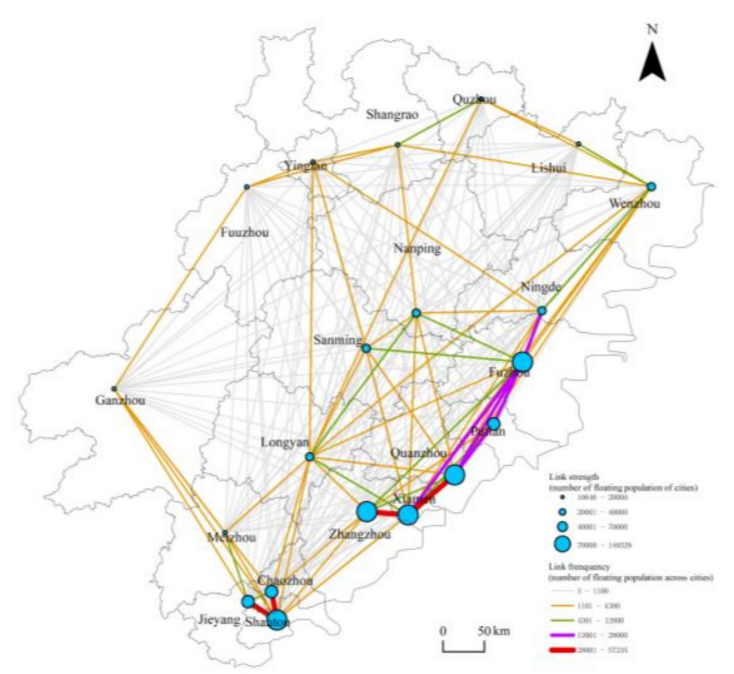

(b)

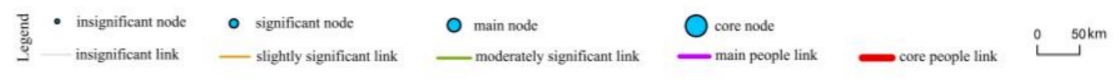

Figure 5. Functional network of the Economic Zone of the WSTS on (a) weekdays and (b) weekends.

\subsubsection{Innovation Network}

The present research used the number of shared patents (i.e., co-patents) between cities to characterize the strength of intercity innovation cooperation links, and we created an innovation network of the Economic Zone of WSTS on the basis of these links (Figure 6).

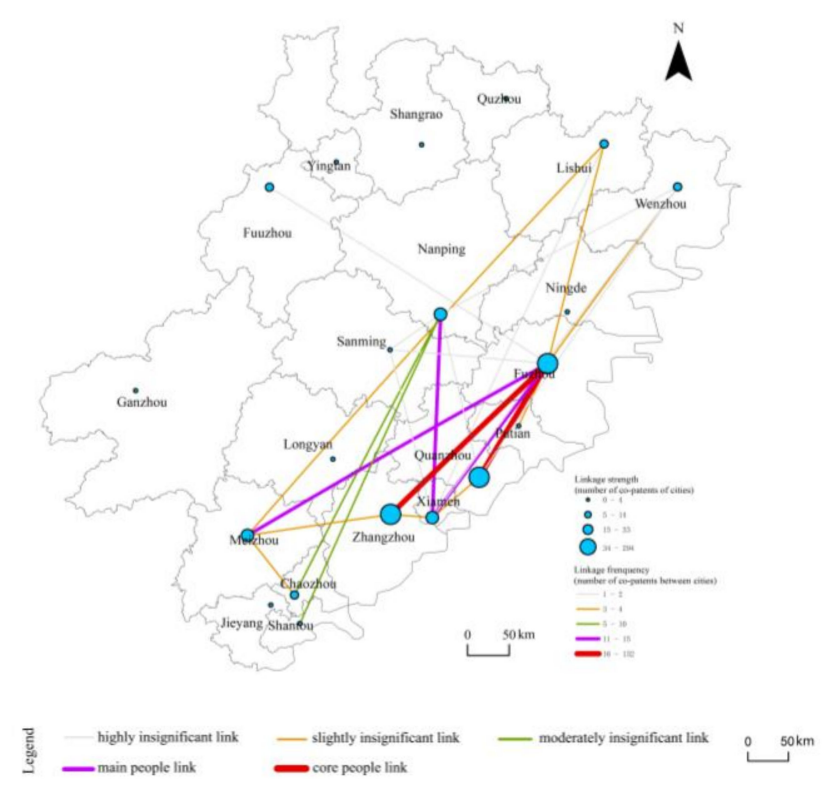

Figure 6. Innovation network of the Economic Zone of the WSTS.

The co-patent referred to the invention patents that had been jointly applied for by multiple entities and that had been approved by the government [39]. It was the most direct and effective way to reflect knowledge sharing and innovation cooperation. The use of co-patents to conduct research within an innovative network has been recognized by scholars [40-42]. Referring to the threshold division of natural break points, this study defined less than 10 intercity co-patents to be insignificant links, defined more than 10 but less than 15 intercity co-patents to be main innovation cooperation links, and defined more than 15 co-patents to be core innovation cooperation links. Figure 3 shows 
that from 2000 to 2018, the core innovation cooperation links were made in Fuzhou-Quanzhou and Fuzhou-Zhangzhou. The main innovation cooperation links were in Xiamen-Nanping, Xiamen-Fuzhou, and Fuzhou-Meizhou. In addition, Fuzhou was the main innovation cooperation node in the region.

\subsection{Analysis of Network Centrality}

This study used degree of centrality as the indicator of urban centrality. The functional network was a directed network, and the degree of centrality in the network was divided into in-degree centrality and out-degree centrality. To identify the threshold division of natural break points, we took an appropriate value of a threshold to determine whether having a tight functional or innovative relation existed between cities. If the connection was greater than the threshold, the value of intercity link was recorded as 1 , and the opposite was recorded as 0 . Finally, we added the value of intercity links and obtained each city's degree of centrality.

This study analyzed node characteristics of the city networks according to connection strength (Table 2), radiation capacity, and absorptive capacity (Table 3, Figure 7) of the cities characterized by the degree of centrality. The results showed that from the perspective of the connection strength of one city compared with other cities in the region, the common characteristics of a functional network and an innovation network were as follows: Fuzhou, Xiamen, Quanzhou, Nanping, Wenzhou, and Ganzhou formed a ring-shaped area with close connections to other cities in the economic zone.

The differences between these two networks' characteristics were as follows.

From the perspective of connection strength, Xiamen, Quanzhou, Fuzhou, and Ganzhou ranked in the top four on weekdays and weekends in the functional network, which reflected their strong competitiveness. In addition, most cities had stronger connection strength on weekends than on weekdays, which reflected the strong demand for cross-city tourism of the regional people on weekends. In addition, in the innovation network, the connection strength of Fuzhou and Xiamen ranked in the top two. Ganzhou, Jieyang, Longyan, Ningde, Shangrao, Yingtan, and Quzhou, however, did not have any innovation cooperation with other cities in the region during this period. By combining both networks, Xiamen and Fuzhou had the closest connections to other cities in the region from the perspective of function and innovation.

Table 2. The degree of centrality of the city networks in the Economic Zone of WSTS (connection strength).

\begin{tabular}{cccccc}
\hline Cities & $\begin{array}{c}\text { Functional Network } \\
\text { (on Weekdays) }\end{array}$ & Cities & $\begin{array}{c}\text { Functional Network } \\
\text { (on Weekends) }\end{array}$ & Cities & $\begin{array}{c}\text { Innovation } \\
\text { Network }\end{array}$ \\
\hline Fuzhou & 17 & Ganzhou & 17 & Fuzhou & 9 \\
Xiamen & 17 & Fuzhou & 16 & Xiamen & 7 \\
Ganzhou & 15 & Quanzhou & 16 & Nanping & 6 \\
Wenzhou & 14 & Xiamen & 16 & Meizhou & 4 \\
Zhangzhou & 14 & Nanping & 15 & Wenzhou & 4 \\
Nanping & 14 & Longyan & 15 & Lishui & 3 \\
Quanzhou & 13 & Zhangzhou & 15 & Quanzhou & 3 \\
Putian & 12 & Wenzhou & 13 & Sanming & 3 \\
Fuuzhou & 11 & Putian & 12 & Zhangzhou & 3 \\
Sanming & 11 & Sanming & 12 & Chaozhou & 2 \\
Shantou & 11 & Yingtan & 12 & Fuuzhou & 1 \\
Shangrao & 11 & Fuuzhou & 11 & Putian & 1 \\
Longyan & 9 & Ningde & 11 & Shantou & 1 \\
Ningde & 9 & Shangrao & 11 & Ganzhou & 0 \\
Chaozhou & 8 & Chaozhou & 9 & Jieyang & 0 \\
Jieyang & 8 & Jieyang & 9 & Longyan & 0 \\
Meizhou & 8 & Shantou & 9 & Ningde & 0 \\
Quzhou & 8 & Quzhou & 8 & Quzhou & 0 \\
Yingtan & 7 & Meizhou & 7 & Shangrao & 0 \\
Lishui & 5 & Lishui & 6 & Yingtan & 0 \\
\hline
\end{tabular}


This study measured an urban area's radiation and absorption ability by analyzing in-degree centrality and out-degree centrality in regional cities compared with other cities in China. The results showed that Xiamen, Fuzhou, Quanzhou, Shangrao, and Ganzhou were within the top six of in-degree centrality and out-degree centrality on both weekdays and on weekends (Table 3), which reflected their strong radiation and absorption ability. In addition, on weekdays, the average out-degree centrality of cities in the region was 22.5 , and the average in-degree centrality was 22.3. On weekends, the average out-degree centrality of cities in the region was 18.4, and the average in-degree centrality was 18.7. This finding showed that urban radiation and absorption ability were almost the same on weekdays and on weekends. Compared with urban radiation and absorption ability on weekdays, it decreased on weekends.

Therefore, according to urban centrality characterized by the degree of centrality, it was evident that Fuzhou and Xiamen ranked in the first level of centrality; Quanzhou, Wenzhou, and Zhangzhou ranked in the second level of centrality, and other cities ranked in the third level of centrality.

Table 3. The degree centrality of functional network of the Economic Zone of WSTS (in-degree centrality and out-degree centrality).

\begin{tabular}{|c|c|c|c|c|c|c|c|}
\hline \multicolumn{4}{|c|}{ Weekday } & \multicolumn{4}{|c|}{ Weekend } \\
\hline Cities & $\begin{array}{l}\text { Out-Degree } \\
\text { Centrality (c) }\end{array}$ & Cities & $\begin{array}{c}\text { In-Degree } \\
\text { Centrality (a) }\end{array}$ & Cities & $\begin{array}{l}\text { Out-Degree } \\
\text { Centrality (d) }\end{array}$ & Cities & $\begin{array}{c}\text { In-Degree } \\
\text { Centrality (b) }\end{array}$ \\
\hline Xiamen & 47 & Xiamen & 41 & Wenzhou & 34 & Xiamen & 36 \\
\hline Fuzhou & 43 & Ganzhou & 38 & Xiamen & 33 & Ganzhou & 32 \\
\hline Wenzhou & 41 & Fuzhou & 36 & Fuzhou & 30 & Shangrao & 30 \\
\hline Quanzhou & 37 & Shangrao & 34 & Ganzhou & 30 & Fuzhou & 28 \\
\hline Shangrao & 37 & Wenzhou & 34 & Shangrao & 29 & Quanzhou & 28 \\
\hline Ganzhou & 35 & Quanzhou & 31 & Quanzhou & 27 & Wenzhou & 28 \\
\hline Fuuzhou & 21 & Fuuzhou & 25 & Fuuzhou & 20 & Fuuzhou & 21 \\
\hline Quzhou & 20 & Yingtan & 22 & Quzhou & 17 & Quzhou & 17 \\
\hline Zhangzhou & 18 & Quzhou & 20 & Meizhou & 15 & Shantou & 17 \\
\hline Nanping & 17 & Zhangzhou & 19 & Nanping & 15 & Zhangzhou & 17 \\
\hline Shantou & 17 & Shantou & 18 & Shantou & 15 & Jieyang & 15 \\
\hline Jieyang & 16 & Jieyang & 17 & Zhangzhou & 14 & Meizhou & 14 \\
\hline Yingtan & 16 & Nanping & 17 & Jieyang & 14 & Nanping & 14 \\
\hline Chaozhou & 13 & Meizhou & 15 & Chaozhou & 13 & Chaozhou & 12 \\
\hline Meizhou & 13 & Chaozhou & 14 & Yingtan & 12 & Lishui & 12 \\
\hline Putian & 13 & Ningde & 14 & Ningde & 11 & Ningde & 11 \\
\hline Lishui & 12 & Putian & 14 & Sanming & 11 & Putian & 11 \\
\hline Ningde & 12 & Sanming & 13 & Lishui & 10 & Yingtan & 11 \\
\hline Sanming & 11 & Lishui & 12 & Putian & 10 & Longyan & 10 \\
\hline Longyan & 10 & Longyan & 12 & Longyan & 8 & Sanming & 10 \\
\hline
\end{tabular}

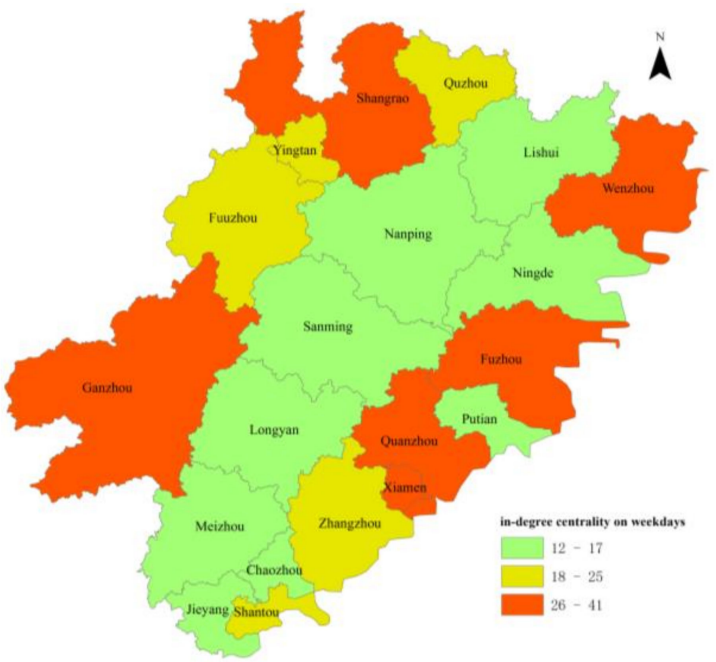

(a)

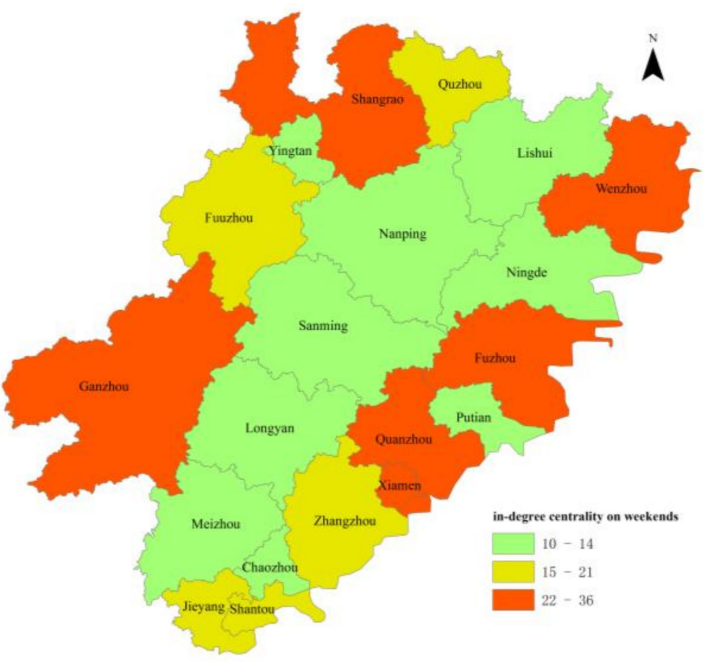

(b)

Figure 7. Cont. 


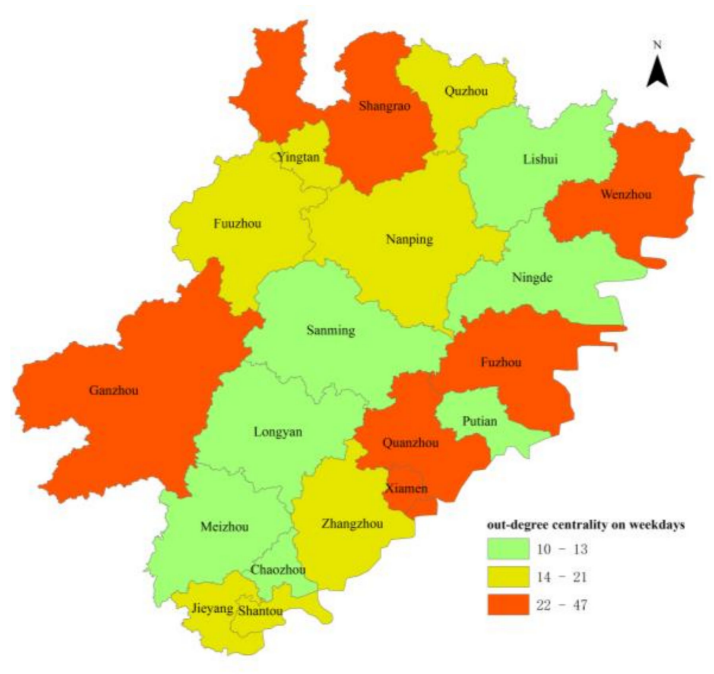

(c)

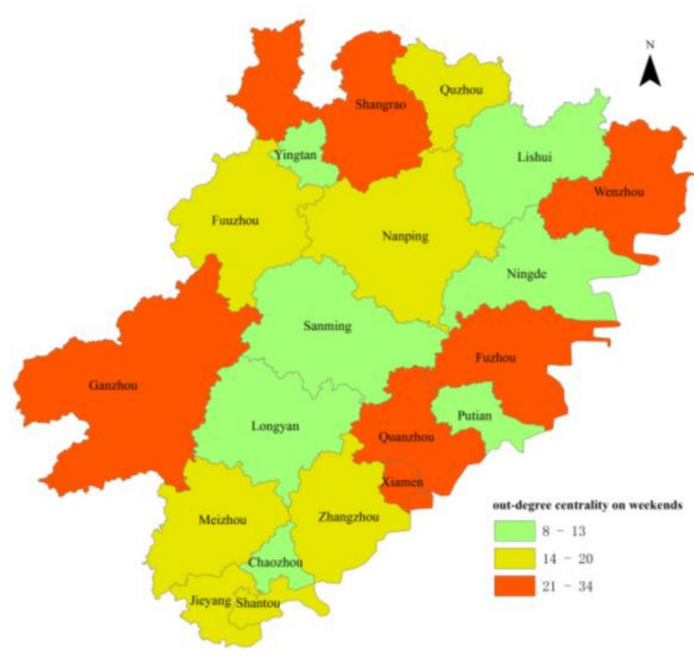

(d)

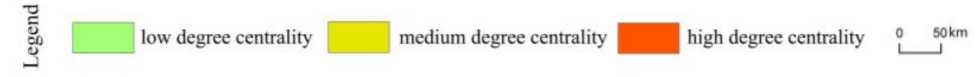

Figure 7. Spatialization of degree centrality of functional networks in the Economic Zone of WSTS, including in-degree centrality on (a) weekdays and (b) weekends, and out-degree centrality on (c) weekdays and (d) weekends.

\subsection{Identification of Spatial Organization}

The study used the Fast Unfolding Community Detection method to identify spatial organization. The approach continually evaluated and compared the benefits generated by each city being divided into different communities through an index of modularity, and finally obtained the optimal solution. As the key index, modularity reflected the obviousness of the community structure and could be used to evaluate the availability of the result, and these values were directly proportional. When the modularity was greater than 0.3 , we regarded it a reliable result.

The group structure was an important feature of a network, which was composed of multiple groups. The degree of closeness within a group was higher than that outside the group. Different group structures affected the geospatial organization of a city. We used the Fast Unfolding Community Detection algorithm based on modularity in Gephi [38] to divide networks into groups (Figure 8). The study found that the functional network could be divided into four types of groups on weekdays, and the modularity was 0.34 . In addition, the functional network could be divided into three types of group on weekends, and the modularity was 0.40 . The modularity of weekdays and weekends was within the normal range, so the group structure of the network was obvious. We divided the innovation network into two types of groups and the modularity was 0.17 , which indicated that the group structure in the network was not obvious. Because the obvious structure of groups was the necessary basis for the analysis of the spatial organization of the city networks, the study analyzed the spatial organization of the region only through the functional network.

In a functional network, on weekdays, the geographic proximity of groups was weak, and the feature of an enclave was obvious. This showed that there were many long-distance business connections. Among them, Yingtan, Shangrao, Quzhou, and Fuzhou, which were weak in centrality, constituted a group, which we called the "Ying-Shang-Qu" group. The group's shape was relatively complete. Quanzhou, which had a strong centrality, and Chaozhou, Shantou, Jieyang, and Putian, which were weak in centrality, constituted a group, which we called the "Quan-Chao-Shan" group. The group's shape was scattered. Xiamen, which was one of the cities with the strongest centrality, Wenzhou, and Ganzhou, which had a strong centrality, and Nanping, Lishui, Longyan, and Meizhou, which were weak in centrality, constituted a group, which we called the "Xia-Wen-Gan" group. The group's shape was also scattered. Fuzhou, which was another one of the cities with the strongest 
centrality, and Ningde, Zhangzhou, and Sanming, which were weak in centrality, constituted a group, which we called the "Fu-Ning-Zhang" group. Although the group included individual cities exhibiting the characteristics of enclave, cities in the middle of the region made up the main body. Therefore, we found that Xiamen and Zhangzhou were special, because they had close relationships with cities that did not border them, in particular, Xiamen. This relationship reflected the wide range of influence of Xiamen.

On weekends, the groups divided by functional network had obvious characteristics of geographic proximity, and all groups were composed of geographically neighboring cities. The groups were in a group shape and were relatively complete. Among them, Meizhou, Chaozhou, Shantou, and Jieyang, which were weak in centrality, constituted a group, which we called the "Mei-Chao-Shan" group. Xiamen, which was one of the cities with the strongest centrality, Quanzhou, which had strong centrality, and Zhangzhou and Putian, which were weak in centrality, constituted a group, which we called the "Xia-Quan-Zhang" group. Fuzhou, which was another one of the cities with the strongest centrality, Whenzhou and Ganzhou, which were strong in centrality, and other cities with weak centrality constituted a group, which we called the "Fu-When-Gan" group.

The members of these groups were scattered on weekdays and concentrated on weekends. In addition, the "'Ying-Shang-Qu" group on weekdays and the "Mei-Chao-Shan" group on weekends lacked cities with strong centrality.

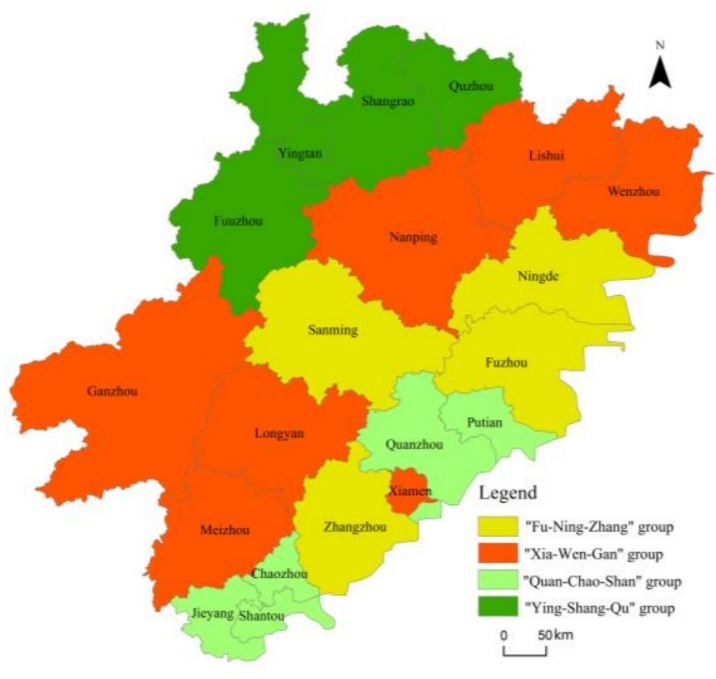

(a)

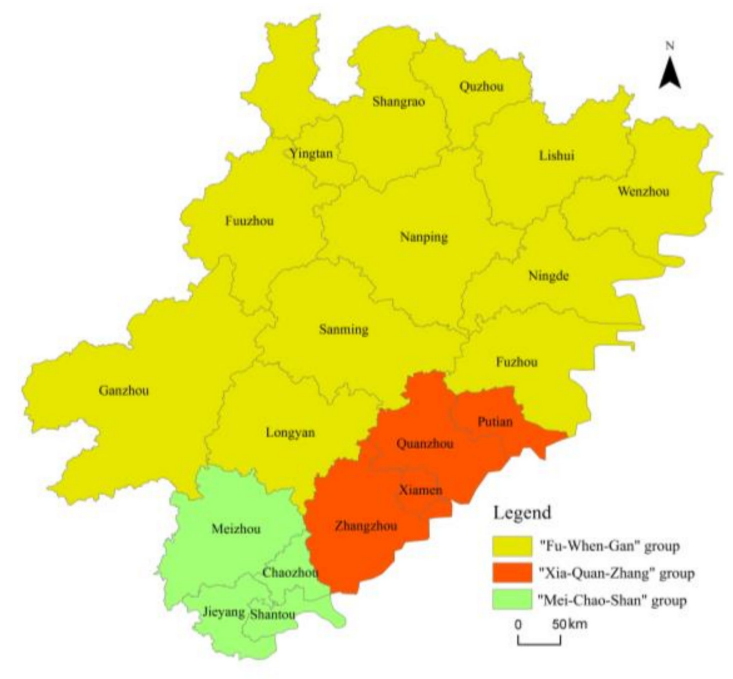

(b)

Figure 8. Group spatial distribution of functional network on (a) weekdays and (b) weekends in the Economic Zone of WSTS.

\subsection{Analysis of Symmetry}

We used node symmetry to measure the proportion of inflows and outflows of elements in a city. We used link symmetry to measure the direction and degree of difference in the flow of elements in a link, which reflected the unequal flow of intercity elements. This paper described the symmetry of functional networks in the Economic Zone of WSTS using node symmetry and link symmetry. In addition, we judged the main direction of people flows in each city and between two cities and measured the differences of intercity people's bidirectional flow. We finally revealed the relationships of those cities with strong centrality, as well as other cities in the group. Because the analysis of symmetry required directional data, whereas innovative cooperation between cities did not have the attribute of direction, the study analyzed the analysis of symmetry only through the functional network. 


\subsubsection{Analysis of Node Symmetry}

To reflect the size of the floating population across cities, this paper optimized node symmetry by replacing degree of centrality with the size of the floating population across cities. We measured the degree of people net inflow or people net outflow of cities according to node symmetry. The closer the node symmetry was to 1 , the more serious the net inflow of people to cities. The closer the node symmetry was to -1 , the more serious the net outflow of people to cities.

We analyzed the characteristics of city nodes in functional networks through node symmetry (Table 4) and spatialized these characteristics (Figure 9). The results showed that on weekdays and weekends, cities with a higher proportion of people outflows than inflows were distributed in the eastern part of the region, among them, on weekdays, the proportion of people outflows in Wenzhou, Fuzhou, and Xiamen, and that this proportion was higher than the proportion of people inflows. As such, they mainly showed an outflow of people. On weekends, the proportion of people outflows in Fuzhou, Xiamen, Shantou, and Wenzhou was higher than the proportion of people inflows. This suggested that as cities that were strong in centrality, Xiamen, Fuzhou, and Whenzhou showed net outflow of people on weekdays and weekends. In addition, 16 cities had a higher proportion of people inflows than the proportion of people outflows both on weekdays and weekends, including Chaozhou, Fuuzhou, Ganzhou, Jieyang, Lishui, Longyan, Meizhou, Nanping, Ningde, Putian, Quzhou, Quanzhou, Sanming, Shangrao, Yingtan, and Zhangzhou, and 87.5\% of them were cities that were weak in centrality. The node symmetry of Longyan and Ganzhou ranked in the top three on weekdays and weekends. As for Shantou, the proportion of people inflows was relatively higher on weekdays, whereas the proportion of people outflows was relatively higher on weekends, which indicated that it mainly was manifested in the inflow of people on weekdays and the outflow of people on weekends.

Table 4. Node symmetry of functional network in the Economic Zone of WSTS.

\begin{tabular}{cccc}
\hline Cities & Weekday & Cities & Weekend \\
\hline Meizhou & 0.195 & Zhangzhou & 0.108 \\
Longyan & 0.156 & Longyan & 0.075 \\
Ganzhou & 0.151 & Ganzhou & 0.068 \\
Quzhou & 0.114 & Nanping & 0.067 \\
Fuuzhou & 0.100 & Ningde & 0.063 \\
Sanming & 0.098 & Meizhou & 0.056 \\
Shangrao & 0.093 & Shangrao & 0.054 \\
Ningde & 0.079 & Chaozhou & 0.052 \\
Chaozhou & 0.077 & Lishui & 0.052 \\
Putian & 0.066 & Fuuzhou & 0.051 \\
Zhangzhou & 0.066 & Quanzhou & 0.049 \\
Yingtan & 0.065 & Putian & 0.042 \\
Lishui & 0.058 & Quzhou & 0.040 \\
Nanping & 0.057 & Sanming & 0.029 \\
Shantou & 0.032 & Jieyang & 0.025 \\
Quanzhou & 0.022 & Yingtan & 0.017 \\
Jieyang & 0.019 & Shantou & -0.023 \\
Wenzhou & -0.014 & Wenzhou & -0.027 \\
Xiamen & -0.051 & Fuzhou & -0.075 \\
Fuzhou & -0.115 & Xiamen & -0.090 \\
\hline
\end{tabular}




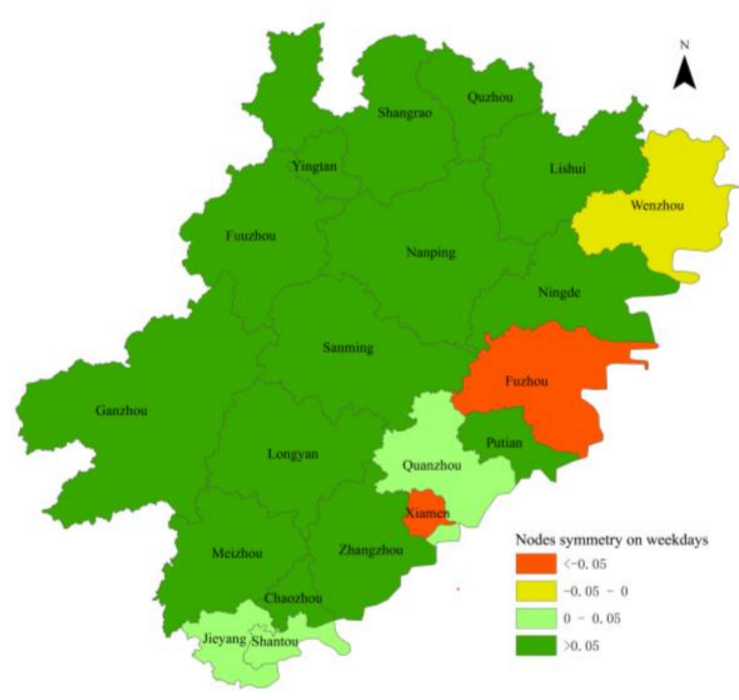

(a)

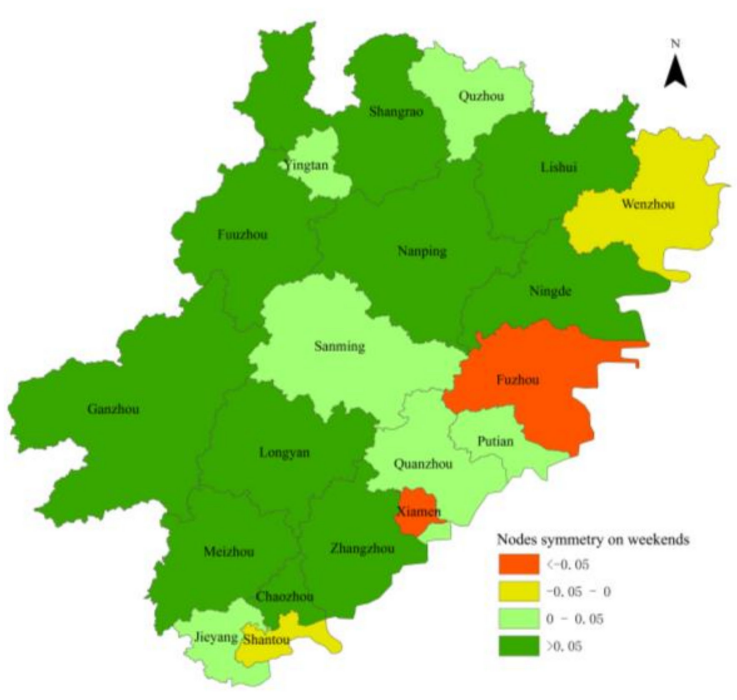

(b)

population slightly net outflow

population slightly net inflow

Figure 9. Nodes symmetry of functional network in the Economic Zone of WSTS on (a) weekdays and (b) weekends.

\subsubsection{Analysis of Link Symmetry}

The link symmetry proposed by Liu Zhen reflected the difference in the proportion of factor flows between two cities and the direction of the dominant flow [37]. When the link symmetry was 0 , the corresponding link was a bidirectional equivalent flow. The closer the absolute value of the link symmetry was to 1 , the greater the difference in the size of the floating population across cities, and the less sustainable the urban relation.

According to link symmetry, we analyzed the direction and difference in the exchange of people to reflect the unequal flow of people crossing to cities, and thus revealed relationships of unequal attraction between cities. As for city-dyads, the total size of the floating population across cities was relatively small, the intercity people flows were relatively inactive, and the corresponding link symmetries had contingency. Therefore, this study eliminated them, with a threshold of 100 person-times, and only the city-dyads with a floating population more than 100 person-times across cities were taken as research objects. Referring to the threshold division of natural break points, the study defined the links with asymmetry less than 0.05 as almost symmetric links, defined the links with asymmetry greater than 0.05 but less than 0.15 as slightly asymmetric links, defined the links with asymmetry greater than 0.15 but less than 0.3 as moderately asymmetric links, defined the links with asymmetry greater than 0.3 but less than 0.7 as significantly asymmetric links, and defined the links with asymmetry greater than 0.7 as highly asymmetric links. This study analyzed symmetrical relationships between cities with strong centrality, as well as other cities within the group, and thus we could further characterize the structure of the functional network (Figure 10).

The results showed that on weekdays, in the "Xia-Wen-Gan" group, for Xiamen, which was one of cities with the strongest centrality in the region, people flowed from Xiamen to Meizhou, Nanping, and Longyan in a moderately asymmetrical way, and people flowed from Xiamen to Wenzhou in a slightly asymmetrical way. For Wenzhou and Ganzhou, which had strong centrality, people flowed from Meizhou and Nanping to Ganzhou, and from Wenzhou to Nanping in a moderately asymmetrical way. In addition, people flowed from Whenzhou to Ganzhou and Longyan in a slightly asymmetrical way. Therefore, people in Xiamen and Wenzhou flowed in a mainly asymmetrical way to cities with weak centrality. In the "Fu-Ning-Zhang" group, for Fuzhou, which was one of cities with the strongest centrality in the region, people flowed from Fuzhou to Zhangzhou and Sanming in a moderately 
asymmetrical way. People also flowed from Fuzhou to Ningde in a slightly asymmetrical way. In the "Quan-Chao-Shan" group, for Quanzhou, which had strong centrality, people flowed from Chaozhou and Shantou to Quanzhou in a slightly asymmetrical way. On weekends, in the "Xia-Quan-zhang" group, for Xiamen, people flowed from Xiamen to Zhangzhou, Quanzhou, and Putian in a slightly asymmetrical way. In the "Fu-Wen-Gan" group, for Fuzhou, people flowed from Fuzhou to Yingtan in a highly asymmetrical way. People flowed from Fuzhou to Longyan, Quzhou, and Ganzhou in a significantly asymmetrical way. People also flowed from Fuzhou to Shangrao in a moderately asymmetrical way. For Wenzhou, people flowed from Longyan to Whenzhou, and from Whenzhou to Yingtan in a highly asymmetrical way. People flowed from Ganzhou to Whenzhou in a significantly asymmetrical way. People also flowed from Whenzhou to Sanming in a moderately asymmetrical way. For Ganzhou, people flowed from Ganzhou to Nanping, Ningde, and Yingtan, and from Shangrao to Ganzhou in a highly asymmetrical way. People also flowed from Fuuzhou to Ganzhou in a significantly asymmetrical way.

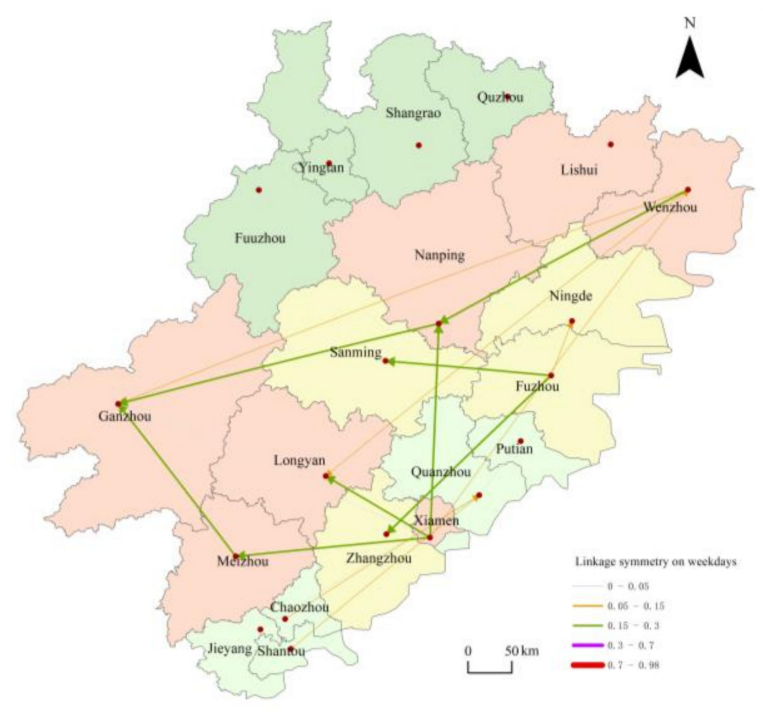

(a)

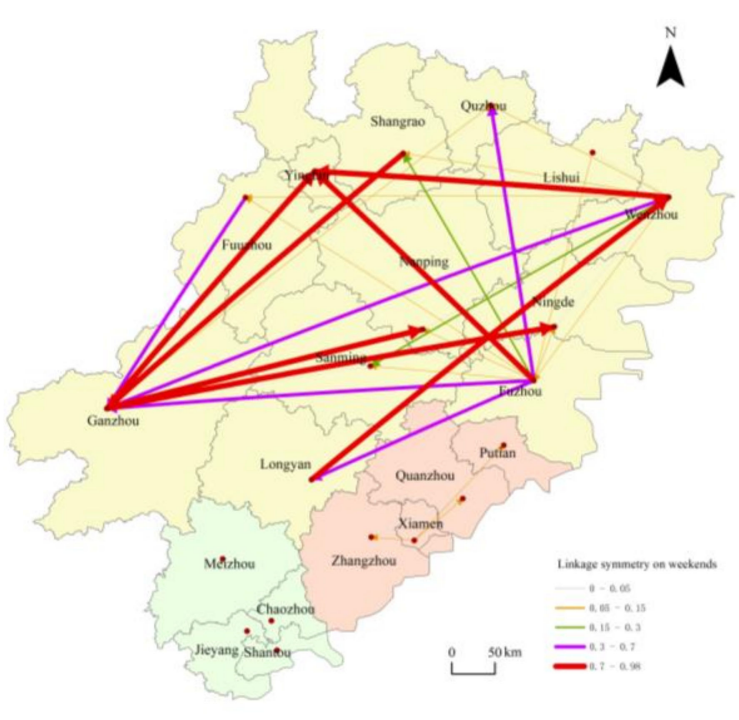

(b)

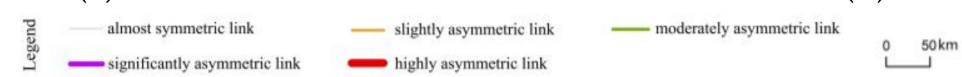

Figure 10. Link symmetry of functional network in the Economic Zone of WSTS on (a) weekdays and (b) weekends.

\section{Discussion and Conclusions}

\subsection{Discussion}

This section discusses intercity relationships at the regional scale and the local scale of the Economic Zone of the WSTS. We subdivided our examination of the local scale to include inter-provincial, intra-provincial, and group perspectives.

From the regional scale perspective, we found that a multilevel spatial network structure in the region had taken shape. Among the cities in this study, Xiamen, Fuzhou, and Wenzhou created a spillover effect to other cities and experienced a phenomenon of depolarization. Other cities, especially cities in the middle and west of the region, which are all small and midsize cities, experienced a net inflow of people. This result was similar to those from $\mathrm{Xu}$ 's study, which constructed a regional economic interaction evaluation system. $\mathrm{Xu}$ found that the overall urbanization level of the cities in the middle and west of the region was low but that the economic growth rate was higher than that of the eastern cities in the region, which are cities with strong centrality [43].

To some extent, this result was inconsistent with Ning's study, which analyzed statistical data and revealed that the talents were outflowing from Jiangxi Province to other cities located in the middle and 
west of the region [44]. Differences existed on the time granularity of the research data between these two research studies. The talent flow data in Ning's study were long-term statistical data, whereas the people flow data in this study were short-term data. Conversely, one possible reason for the net people inflow to the cities in the middle and west of the region could be that the economic connections between these cities and other cities in the network were becoming stronger-for example, an increase of industrial investment in the cities or an increase in investment to set up branch offices, which also resulted in an increase in labor and in the number business trips required between the head office and branch offices. These reasons should be further investigated along with the reasons for population flow used in the present work and will be an important focus of our further research. From these results, our study showed that urbanization of small and midsize cities in the region was common. In light of the difficulty of getting the citizenship to move to big cities, the choice of developing small and midsize cities has become a current trend.

From an interprovincial perspective, by identifying spatial organizations, we found that interprovincial business connections were close and that there were many long-distance business connections among cities. These connections reflected the fact that the business environment of the region was free and open. This result was inconsistent with Liu's study, which used a regional economic development coordination degree evaluation system [45]. Liu found, in 2011, that administrative divisions existed among the four provinces in the region, which hindered the flow of production and economic factors. This result showed that the flow of regional interprovincial factors became more liberal and that the region was becoming more integrated. In addition, we found that the primary reason for the flow of people on weekends was for short-distance travel, which was understandable. Because people have a limited amount of time, they tend to travel or recreate in the cities in which they are located or to the surrounding cities on weekends. In addition, on weekdays, each city in the "Ying-Shang-Qu" group and, on weekends, each city in the "Mei-Chao-Shan" group had weak centrality, and these groups did not include any cities with strong centrality. This finding revealed that the polycentric development pattern of the region had not entirely taken shape and needed to improve.

Based on the group analysis in Section 3.3, other than interprovincial people connections, we found cities in Zhejiang Province, Jiangxi Province, or Guangdong Province were members of two different groups on weekdays, and cities in Fujian Province were members of three different groups on weekdays. Isolated cities did not exist for any of the groups in Fujian Province. This result was inconsistent with the results from Liu's study, which revealed that administrative divisions existed between neighboring cities in the same province in the region [45]. However, the results of our study further clarified that the cities in each group in Fujian Province had close relationships and very few administrative divisions existed. Thus, we do not think there are obvious administrative divisions between cities (some of them are neighboring cities) in one group, while we still need to further clarify whether any administrative divisions exist between groups.

Considering the existing regional planning in Fujian Province, it has divided the province into two city regions: Xiamen is the center of one region and is surrounded by Quanzhou, Zhangzhou, and Longyan; Fuzhou is the center of the other region and is surrounded by Sanming, Nanping, Putian, and Ningde. This division was inconsistent with the three city groups in Fujian Province. In the Xiamen-centered city region, Quanzhou, Zhangzhou, and Xiamen belonged to different groups. In addition, in the Fuzhou-centered city region, Putian, Nanping, and Xiamen belonged to different groups. To improve the relationship between planning and status quo, we suggest to adjust the cities contained in these planning regions according to the range of each group, rather than to limit each region to neighboring cities. Another solution is to identify reasons behind this phenomenon to strengthen the connections among the cities in each planed city region, which will be a focus of our further research.

Additionally, we defined the core people link and main people link as links with strong connections. In Fujian Province, we found that Fuzhou had a strong connection with Ningde and Putian, and Xiamen had a strong connection with Zhangzhou and Quanzhou. Thus, this region had formed a city region 
that included Fuzhou, Ningde, and Putian, as well as another city region that included Xiamen, Zhangzhou, and Quanzhou. In addition, in Jiangxi Province, Ganzhou was a city with strong centrality, but the connections between Ganzhou and Fuuzhou, Yingtan, and Shangrao were weak on weekdays. Also, in Zhejiang Province, Whenzhou was a city with strong centrality, but the connection between Whenzhou and Quzhou was weak.

From the group perspective, Quanzhou and Ganzhou had a moderate siphon effect on small and midsize cities within the group on weekdays. Although it accelerated the formation of regional economic growth poles and industrial cities, it easily contributed to the loss of production actors and economical actors, including talent, capital, and labor, in the small and midsize cities. This obviously was an unsustainable development pattern. Meanwhile, Xiamen, Fuzhou, and Whenzhou had a spillover effect on small and midsize cities within the group, in particular in Fuzhou and Whenzhou on weekends. This result suggested that the people flow mode between Xiamen, Fuzhou, or Whenzhou and other cities in the group was sustainable.

\subsection{Conclusions}

In the process of identifying and characterizing the spatial structure of city networks and the balance of the floating population across cities, this study quantitatively characterized the spatial structure and the interrelationships among cities in the Economic Zone of WSTS by coupling the regional and local scales.

The approach characterizing city network structures at regional and local scales can better reflect the role of each city and their intercity relationships. This approach contributes to our understanding of the implications of city networks more comprehensively. By identifying and characterizing the spatial structure of city networks at the local scale and taking the direction of these links into account, this approach can characterize intercity relationships in a microscopic and detailed way, which is consistent with the increasing complexity of city networks.

Furthermore, the effective identification of city network structure is related to the sustainable development of the region, and it can assist in making production factors and economic factors operate more efficiently. Thus, the ability to identify city network structures from multiple scales is conducive to the promotion of sustainability in the region and to improvement in the flowing efficiency of production factors and economic factors. The approach taken in this study has certain application space and reference value in the research of city networks. It is especially relevant in the era of increasing complexity of city networks. The approach also is applicable to the study of intercity relationships at the microlevel and to the study of the balance of intercity element flows.

To promote the efficiency and reasonability of factor flow in the region, we proposed the following policy recommendations:

For the groups that lacked a city with strong centrality, we should focus on the cultivation of growth poles to strengthen the polycentric development pattern and effectively lead the development of these groups. A significant imbalance in the innovation cooperation between cities in the region appears to be weak on the whole, except for those cities with strong centrality. Thus, it is urgent for the region to increase the integral investment on research and development in the future, improve the capacity for innovation of science and technology, and introduce relevant talent. Because of the current dilemma regarding large-scale net outflow of production factors in the Economic Zone of WSTS to the Yangtze River Delta Economic Zone and the Pearl River Delta Economic Zone [46], a clear development orientation and pathway for Xiamen and Fuzhou is needed urgently. These cities have strong centrality in the area, at the national level, and at the international level. We need to evaluate the foundation of urban development and the carrying capacity of resources and the environment to improve the competitiveness and centrality of the region on a larger regional scale. Institutional security should be discussed in depth. For the central and western cities in the region, the local government should develop planning policies to promote the urban development of these cities in the future. 
The Southwestern Synergistic Development Zone Planning and the Northeastern Synergistic Development Zone Planning are typical regional plans in Fujian Province. The former includes Quanzhou, Zhangzhou, Longyan, and Xiamen; the latter includes Ningde, Putian, Nanping, Sanming, and Fuzhou. This planning is inconsistent with the city regions that naturally formed (discussed in Section 3.1.1). The links between Longyan-Xiamen, Nanping-Fuzhou, and Sanming-Fuzhou were weak. Therefore, whether Longyan should belong to the Southwestern Synergistic Development Zone, and whether Nanping and Sanming should belong to the Northeastern Synergistic Development Zone deserves thoughtful consideration. To promote provincial planning in Jiangxi Province, Zhejiang Province, and Guangdong Province, it is necessary to strengthen connections in each province, including links between Zhangzhou-Fuzhou, Zhangzhou-Yingtan, Zhangzhou-Shangrao, Wenzhou-Zhangzhou, Meizhou-Jieyang, Meizhou-Shantou, and Meizhou-Chaozhou.

The present research has some shortcomings, however. The study constructed the functional network from the perspective of people flow, without considering other production factors, such as capital. In addition, to analyze the floating population across cities, the study adopted an empirical hypothesis, but it did not combine questionnaires, interviews, and other field surveys. This will be the direction of further research.

Author Contributions: Y.M. originated the research, designed the research framework, collected data, checked through the whole paper, and provided significant guidance. F.X. conducted the data analysis and discussed the findings.

Acknowledgments: We would like to thank the editor and reviewers for the valuable comments and useful suggestions. This work was supported by the Funds of Education Department of Fujian Province for Distinguished Young scholars (Grant No. 50011522) and supported by the National Natural Science Foundation of China (Grant No. 41501181).

Conflicts of Interest: The authors declare no conflict of interest.

\section{References}

1. Hall, P.; Pain, K. The Polycentric Metropolis; Routledge: London, UK, 2006.

2. Manuel, C. Globalisation, networking, urbanisation: Reflections on the spatial dynamics of the information age. Urban Stud. 2010, 47, 2737-2745.

3. Hui, E.C.M.; Li, X.; Chen, T.; Lang, W. Deciphering the spatial structure of China's megacity region: A new bay area-The Guangdong-Hong Kong-Macao greater bay area in the making. Cities 2018. [CrossRef]

4. Ye, K.; Liu, G.; Shan, Y. Networked or un-networked? A preliminary study on KIBS-based sustainable urban development: The case of China. Sustainability 2016, 8, 509. [CrossRef]

5. Ye, X.; He, C. The new data landscape for regional and urban analysis. GeoJournal 2016, 81, 811-815. [CrossRef]

6. Ye, X.; She, B.; Wu, L.; Zhu, X.; Cheng, Y. An open source toolkit for identifying comparative space-time research questions. Chin. Geogr. Sci. 2014, 24, 348-361. [CrossRef]

7. Liu, X.; Long, Y. Automated identification and characterization of parcels with OpenStreetMap and points of interest. Environ. Plan. B Plan. Des. 2016, 43, 341-360. [CrossRef]

8. Hansen, W.G. How accessibility shapes land use. J. Am. Plan. Assoc. 1959, 25, 73-76. [CrossRef]

9. Zhang, F.; Zhu, X.; Guo, W.; Ye, X.; Hu, T.; Huang, L. Analyzing urban human mobility patterns through a thematic model at a finer scale. ISPRS Int. J. Geo-Inf. 2016, 5, 78. [CrossRef]

10. Harwit, E. Telecommunications and the internet in Shanghai: Political and economic factors shaping the network in a Chinese city. Urban Stud. 2005, 42, 1837-1858. [CrossRef]

11. Gebauer, A.; Nam, C.W.; Parsche, R. Regional technology policy and factors shaping local innovation networks in small German cities. Eur. Plan. Stud. 2005, 13, 661-683. [CrossRef]

12. Camagni, R.; Capello, R. The City Network Paradigm: Theory and Empirical Evidence; Emerald Group Publishing Limited: Bingley, UK, 2004; pp. 495-529.

13. Zhan, C.; Derudder, B.; Peng, Z. Comparing the physical, functional and knowledge integration of the Yangtze River Delta city-region through the lens of inter-city networks. Cities 2018, 82, 119-126. 
14. Van Oort, F.; Burger, M.; Raspe, O. On the economic foundation of the urban network paradigm: Spatial integration, functional integration and economic complementarities within the Dutch Randstad. Urban Stud. 2010, 47, 725-748. [CrossRef]

15. Jiao, J.; Wang, J.; Jin, F.; Wang, H. Impact of high-speed rail on inter-city network based on the passenger train network in China, 2003-2013. Acta Geogr. Sin. 2016, 71, 265-280. (In Chinese)

16. Liu, Z.; Ding, Z.; Bu, S.; Wang, F. The network structure analysis of zhongyuan urban agglomeration based on interactive and traffic flow relationship. Hum. Geogr. 2015, 30, 79-86. (In Chinese)

17. Meng, D.; Feng, X.; Wen, Y. Urban network structure evolution and organizational pattern in Northeast China from the perspective of railway passenger transport. Geogr. Res. 2017, 36, 1339-1352. (In Chinese)

18. Zhuang, D.; Yang, Y.; Jin, S.; Han, R. Evolution of the Yangtze River Delta's city network based on the strategic emerging industries. Sci. Geogr. Sin. 2017, 37, 546-553. (In Chinese)

19. Ye, Q.; Zhang, L.X.; Peng, P.; Huang, J.L. The network characteristics of urban agglomerations in the middle reaches of the yangtze river based on baidu migration data. Econ. Geogr. 2017, 37, 53-59. (In Chinese)

20. Chen, L.; Wang, S.; Yang, R. The urban network structure of Ha-Chang urban agglomerations based on the traffic and information flow. Econ. Geogr. 2017, 37, 74-80. (In Chinese)

21. Lu, S.; Huang, Y.; Zhao, Z.; Yang, X. Exploring the hierarchical structure of china's railway network from 2008 to 2017. Sustainability 2018, 10, 3173. [CrossRef]

22. Wang, J.; Jing, Y. Comparison of spatial structure and organization mode of inter-city networks from the perspective of railway and air passenger flow. Acta Geogr. Sin. 2017, 72, 1508-1519. (In Chinese)

23. Blondel, V.D.; Guillaume, J.L.; Lambiotte, R.; Lefebvre, E. Fast unfolding of communities in large networks. J. Stat. Mech. Theory Exp. 2008, 2008, P10008. [CrossRef]

24. Newman, M.E.J. Fast algorithm for detecting community structure in networks. Phys. Rev. E 2004, 69, 066133. [CrossRef]

25. Narisra, L.; Martin, D.; Tim, S. A theoretical framework and methodology for characterizing national urban systems on the basis of flows of people: Empirical evidence for France and Germany. Urban Stud. 2007, 44, 2123-2145.

26. Wang, J.C. Innovation Spaces: Enterprise Clusters and Regional Development, 1st ed.; Peking University Press: Beijing, China, 2001; pp. 327-330. (In Chinese)

27. Lee, D.S. Towards urban resilience through inter-city networks of co-invention: A case study of US cities. Sustainability 2018, 10, 289. [CrossRef]

28. Chen, W. Research on the Allocation of Innovation Elements in Metropolitan Regional Innovation System. Ph.D. Thesis, Shanghai Jiaotong University, Shanghai, China, 2009. (In Chinese)

29. Lü, L.; Xie, Y.; Huang, R. The comparison of innovation ability hierarchy of three megalopolises in China. Hum. Geogr. 2013, 28, 91-95. (In Chinese)

30. Lü, L.; Li, Y. A Research on Chinese renovation urban system based on urban renovation function. Acta Geogr. Sin. 2010, 65, 177-190. (In Chinese)

31. Li, W.; Jiang, Y. Research of regional city internal and external function relations based on urban flows elements-A case study of taizhou. Econ. Geogr. 2012, 32, 59-65. (In Chinese)

32. De, H.H. Migration and development: A theoretical perspective 1. Int. Migr. Rev. 2010, 44, $227-264$. (In Chinese)

33. Sun, Y.; Yao, S.; Zhang, L. Spatial expansion of urban network for the three coastal agglomerations of china: A study based on integrated traffic information network. Sci. Geogr. Sin. 2018, 38, 827-837. (In Chinese)

34. Li, W.; Jiang, J.; Lou, Y. Research on the structural characteristics in Mid-Zhejiang urban agglomeration based on the relationship analysis. Econ. Geogr. 2009, 29, 1644-1649. (In Chinese)

35. Lu, Z.; Zhang, Q.; Xing, C.; Fan, H.; Deng, L. A centricity study of the interpersonal node space relationship in sns community based on the graph theory-Taken sina micro-blog as an example. Econ. Geogr. 2013, 33, 77-83. (In Chinese)

36. Gao, G.; Luo, Q.; Fan, X.; Li, E.; Li, X. China's rural population inter-provincial flow: Based on the sixth nationwide population census data. Sci. Geogr. Sin. 2015, 35, 1511-1517. (In Chinese)

37. Liu, Z.; Wang, S.; Zhao, M.; Wu, K. Exploratory analysis of directed weighted network of city. Geogr. Res. 2013, 32, 1253-1268. (In Chinese)

38. Zhong, F. Community Detecting Algorithm for Complex Networks. Master's Thesis, Xidian University of Electronic Technology, Xi'an, China, 2012. (In Chinese) 
39. Wang, Q.; Zeng, G.; Lu, G. Structural evolution of innovation networks of China's equipment manufacturing industry. Acta Geogr. Sin. 2016, 71, 251-264. (In Chinese)

40. Ter Wal, A.L.J. The dynamics of the inventor network in German biotechnology: Geographic proximity versus triadic closure. J. Econ. Geogr. 2013, 14, 589-620. [CrossRef]

41. Li, D.; Wang, T.; Wei, Y.; Yuan, F. Spatial and temporal complexity of scientific knowledge network and technological knowledge network on China's urban scale. Geogr. Res. 2015, 34, 525-540. (In Chinese)

42. Cassi, L.; Plunket, A. Research collaboration in co-inventor networks: Combining closure, bridging and proximities. Reg. Stud. 2015, 49, 936-954. [CrossRef]

43. Xu, Z. A Study on the Linkage Development of Regional Economics-Taking Economic Zone on the Western Coast of the Taiwan Straits as an Example. Ph.D. Thesis, Fujian Normal University, Fuzhou, China, April 2010. (In Chinese)

44. Ning, B. Strategy Research on High-Speed Rail Economy Development in Jiangxi. Master's Thesis, Jiangxi University of Finance and Economics, Jiangxi, China, December 2017. (In Chinese)

45. Liu, W. Study on Coordinated Development of Reginal Economy in the Economy Zone of the West Coast of Taiwan Straits. Master's Thesis, Fujian Normal University, Fuzhou, China, June 2011. (In Chinese)

46. Mi, H.; Cao, H.; Pang, L. Location analysis and city competition ability of economic zone on the West Side of the Straits. Econ. Geogr. 2008, 28, 372-375. (In Chinese)

(C) 2019 by the authors. Licensee MDPI, Basel, Switzerland. This article is an open access article distributed under the terms and conditions of the Creative Commons Attribution (CC BY) license (http://creativecommons.org/licenses/by/4.0/). 